\title{
Treatment of acute lymphoblastic leukemia with protocol Hongkong-Indonesia Acute Lymphoblastic Leukemia 97
}

\author{
Johannes Bondan Lukito
}

\begin{abstract}
Background The HK-Ina ALL 97 study protocol is based on the Therapy Study ALL-BFM 95 protocol. Basically, this protocol stratifies the patients into three groups, i.e. standard risk for low risk group (SR), intermediate risk (IR), and high risk (HR) group, and the treatment is directed according to the risk groups.

Objectives To investigate the overall treatment result of childhood ALL in Indonesia and to stratify patients according to biological, clinical criteria, and molecular study that identify the standard and high risk patients with greater precision.

Methods Twenty patients entered in this study; 10 SR, 6 IR and 4 HR groups. Induction phase for SR group consisted of four drugs (phase I'a) for five weeks and three drugs combination (phase I'b) for four weeks. Consolidation phase consisted of four doses of miniHD MTX $\left(2 \mathrm{gram} / \mathrm{m}^{2}\right)$ (protocol M'), reinduction phase used dexamethasone for seven weeks, and maintenance phase consisted of $6 \mathrm{MP}$ and MTX. Boys, who were at higher risk of relapse, were given pulse dexamethasone and vincristine. Induction phase for IR was the same as SR, but four doses of daunorubicin were given to IR group (Ia). Consolidation phase included four doses HDMTX (5 gram $/ \mathrm{m}^{2}$ ). Phase Ib and Protocol II was the same as SR group. Pulse dexamethasone and vincristine was given to all patients. Induction phase for HR group will be the same as IR group. This followed by three blocks of very intensive treatment. Two reinduction phases and maintenance was the same as SR and IR groups.

Results Nineteen of 20 patients achieved complete remission (CR). The patient who could not stand was a 10 years old boy with initial WBC $612 \times 10^{9} / \mathrm{L}$, T-lineage marrow. He died 5 months since the initial diagnosis after treated with HDMTX with dominant CD33 and sepsis. Conclusion The EFS in this study is $95 \%$ for the observation of 5 months through five years and two months. It is still expected that the result fall off in the subsequent year, but it is also expected to be comparable to $70-80 \%$. The very intensive and toxic program for HR group, may improve the EFS, but may also cause secondary AML in the earlier time [Paediatr Indones 2007;47:88-94].
\end{abstract}

Keywords: Childhood ALL, Protocol Hong KongIndonesia Acute Lymphoblastic Leukemia 97
B FM (Berlin-Frankfurt-Munster) ALL Study Group $^{1}$ has performed various studies on treatment of ALL (acute lymphoblastic leukemia) in the past two decades. The superior result has been regarded as one of the best among the various large cooperative groups. ${ }^{2,3}$ Other cooperative groups have also adopted similar protocols of BFM either in part or total. ${ }^{4}$ The Hong Kong - Indonesia (HK-Ina) ALL 97 Protocol is a modification of the BFM 95 protocol. 5-6

Similar protocols are now used by various cooperative groups (Germany, Austria, Switzerland, Italy), EORTC (Belgium, France), Hungarian and Chile in I-BFM-SG. Brief summary of the protocol is outlined in the appendix.

The aims of this study were:

1. To investigate the overall treatment result of acute lymphoblastic leukemia in children in Indonesia.

2. To stratify patients using a combination of biological and clinical criteria together with molecular study. The results obtained can thus be compared with other international groups such as BFM and AIEOP using similar criteria.

From the Department of Child Health, Medical School, Atmajaya University, Atmajaya Teaching Hospital, Pantai Indah Kapuk Hospital, Jakarta, Indonesia.

Reprint requests to: J. Bondan Lukito, MD, Department of Child Health, Medical School, Division of Pediatric Hematology-Oncology, Pantai Indah Kapuk Hospital, Pantai Indah Utara 3, Pantai Indah Kapuk, Jakarta Utara 14460. 


\section{Methods}

To be enrolled in this study, a parent had to give written informed consent. Outcome analysis of this protocol was started in September 2006.

\section{Diagnostic procedure}

Bone marrow aspiration (BMA) was performed and evaluated initially at PIK Hospital. Marrow specimen were also sent to Dharmais National Cancer Center, Jakarta and Queen Mary Hospital Lab., The University of Hong Kong for full color immunophenotyping, cytogenetic, and other studies as indicated.

Steps for the diagnostic procedure were:

1. Cytomorphological examination of bone marrow and peripheral blood performed on minimal 500 nucleated cells in area in which erythrocyte morphology was conserved.

2. Cytochemistry of bone marrow. The following tests were performed: (a) myeloperoxidase: $<3 \%$ of blast; and (b) Sudan Black: $<3 \%$ of blast.

3. Immunophenotyping of bone marrow. The following antibody panel were performed:

- HLA-DR

- $\quad$ B-Lineage markers: CD10, CD19, CD22, CyIgM, SmIg (kappa, lambda)

- T-Lineage markers: CD3, CD5, CD7

- Myeloid markers: CD13, CD33

- Definition of positive: $>25 \%$ flow (gated mononuclear fraction); $>15 \%$ APAAP (blast cells)

Definition of ALL subgroup:

- B precursor:

Early pre-B: at least $2 \mathrm{~B}$ lineage antigens positive but CD10 -,

Common pre-B: at least $2 \mathrm{~B}$ lineage antigens positive but $\mathrm{CD} 10+$,

Pre-B: at least 2 B lineage antigens positive but $\mathrm{CyIgM+,}$

B: at least $2 \mathrm{~B}$ lineage antigen positive but kappa or lamda+

- $\quad \mathrm{T}$ cell: at least $2 \mathrm{~T}$ antigens positive (except $\mathrm{CD} 7+$ on its own is acceptable)

- Hybrid lymphoid leukemia (mixed lineage lymphoblastic leukemia): coexpression on blast cells of two myeloid antigens in $>20 \%$ of lymphoblast of $\mathrm{T}$ or $\mathrm{B}$ origin i.e. of cells positive: myeloid $+\mathrm{T}$ or $\mathrm{B}=120 \%$.

- Result to be reported according to ISCN guideline (a minimum of 20 metaphases should be examined).

4. Cytogenetic study of bone marrow

5. Molecular study for BCR/ABL, MLL/AF4, EA2/PBXI and DNA Index (optional but advisable).

\section{Problems in diagnosis}

Two problems arose related to diagnosis. The first one was difficulty in performing marrow aspiration; in this case, we repeated the aspiration at other site. A dry tap per se was an indication for trephine biopsy, but adequate study of the immunophenotyping may not be possible with trephine biopsy specimen. Peripheral blood with $>30 \%$ blast may be adequate study for immunophenotyping.

The second problem was to determine the diagnosis of CNS disease at onset. Index of suspicion was highest in children $<1$ year and hyperleuko-cytosis. A diagnosis of primary CNS involvement was made in the following situations:

1. WBC $>5 / \mu \mathrm{l}$ with blast in the cytospin fluid.

2. Cranial nerve deficit even with negative blast in CSF.

3. Brain tissue involvement even with negative blast in CSF.

Under the following conditions, two more doses of triple $\mathrm{IT}^{7}$ would be given on day eight and day 22, but they were not treated as CNS disease:

1. CNF cell count $\leq 5 / \mu 1$, but leukemic blast present.

2. Blood contaminated CSF with peripheral blood WBC $>50 \times 10^{4} / \mathrm{L}$ or leukemic blood present.

\section{Statistical considerations}

The primary objective of this study was estimation of event-free survival (EFS) for this cohort. Time to an adverse event was defined as time from enrollment to first event (induction failure, relapse, second malignancy or death). All patients without an event were recorded as date of last contact. Patients with delay in treatment due to toxicity were included in the analysis. Event-free and overall survival estimates were com- 
puted by the method of Kaplan and Meier. The worst degree of toxicity per course was recorded for each patient. Dosage decrement was analyzed for each aspect of study using the formula exposure, i.e. intensity $=$ dose intended/dose delivered X 100, to quantify the toxicity associated with continuation therapy.

\section{Results}

Twenty patients were enrolled in the study. They consisted of 10 patients with low risk, six with moderate risk, and four with high risk. The characteristics of the patients are depicted in Table 1.

\section{Induction responses and event-free survival}

Nineteen of the 20 patients achieved complete remission; the only one who expired was a 10 -year old boy, who came with initial peripheral WBC $612 \times 10^{9}$ / L comprising mostly blast cells, marrow aspirate showed hypercellular marrow practically replaced by sheets of blast with L1 morphology, immunophenotyping showed T-lineage marrow CD1a, CD2, CD3, CD7. Tdt was weak, aberrant expression CD79a and DNA index 1.032. He showed negative for a panel of B-cell and myeloid associated antigen and positive for stem cell marker CD34. The cytogenetic study showed karyotype 46, XY, add (1) (p34),9qh+ 5$\rangle$. The overall diagnosis was precursor T-cell acute lymphoblastic leukemia by WHO terminology. The patient developed severe tumor lysis syndrome during the first eight days monotherapy with prednisolone, but his hemogram was perfectly normal on day 14. Bone marrow aspiration on weeks five and 12 were reported in normal range, he went through consolidation with four doses HDMTX $5 \mathrm{gram} / \mathrm{m}^{2} \mathrm{com}$ bined with 8MP for eight weeks smoothly, but on reinduction on week 22, he developed severe marrow depression with septicemia. Repeated immunophenotyping showed CD33 dominant with some aberrant CD2 and CD7. He died with possible new lineage AML relapse, severe marrow depression and sepsis.

\section{Toxicity}

From 20 evaluable patients, a total 180 mild to moderate and seven severe signs of toxicity were reported.

Table 1. Patient's Characteristics

\begin{tabular}{lccc}
\hline Characteristics & Low risk & Moderate & High risk \\
\hline Enrolled patients & 10 & 6 & 4 \\
Eligible patients & 10 & 6 & 4 \\
WBC (median x 1000) & & & \\
$\quad$ Initial & 26.80 & 12.55 & 53.65 \\
$\quad 8^{\text {th days }}$ & 2.35 & 3.07 & 14.25 \\
$\begin{array}{l}\text { Blast cells (median x 1000) } \\
\text { Initial }\end{array}$ & 15.70 & 5.60 & 32.10 \\
$\quad 8^{\text {th days }}$ & 0.65 & 1.08 & 3.45 \\
$\begin{array}{l}\text { Age at diagnosis } \\
\quad \text { Mean + SD) }\end{array}$ & & & \\
CNS disease at & $4.5+2.1$ & $4.5+2.5$ & $11.9+3.6$ \\
$\quad$ diagnosis & 0 & 0 & $2(10 \%)$ \\
Gender & & & 3 \\
$\quad$ Boy & 1 & 3 & 1 \\
$\quad$ Girl & 9 & & \\
\hline
\end{tabular}

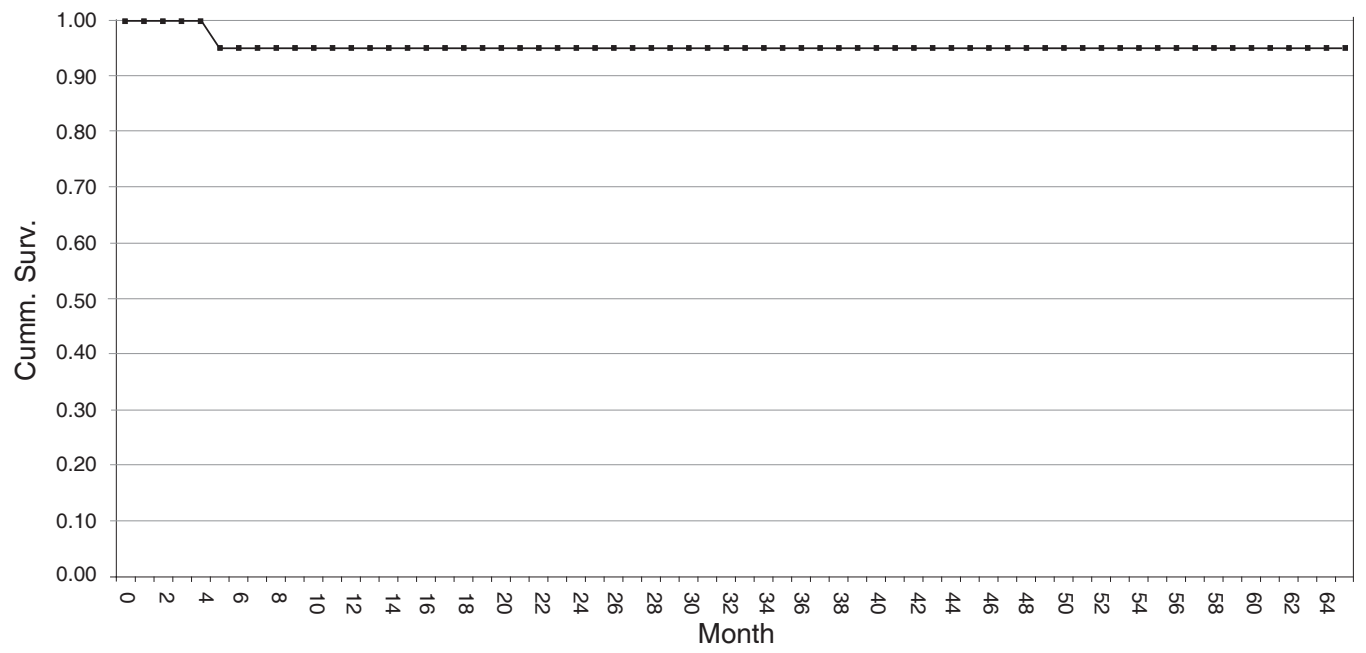

Figure 1. Event-free survival (EFS) for patients and by disease 
Some of our patients showed allergic hypersensitivity, pancreatitis, hepatitis, thrombotic events due to asparginase administration. The most common toxicities were neutropenia, thrombocytopenia, mucositis and sepsis. One high risk patient with systemic fungal infection experienced toxicity during induction consolidation. The severe marrow depressions were clustered: (1) At consolidation (induction I'b, Ib, IIb and II'b), where series of cytarabine were given together with 6MP/6TG and vincristine etc); we often modified or omitted this part and (2) During three blocks of consolidation for high risk patients, two to three doses of granulocyte colony stimulating factor (GCSF) were administered. There was almost no significant side effect during HDMTD per se. Our total duration of induction (induction, consolidation and reinduction) for low risk and moderate risk were 32 weeks and high risk was 44 weeks. The total overall duration of treatment was two years. (Table 2)

\section{Discussion}

During the past decade, the cure rate for childhood acute lymphoblastic leukemia in most developed countries reached $63-83 \%$. The success can be principally attributed to effectiveness of risk directed therapy developed through well-designed clinical trial. We stratified the patients into low, intermediate, or high risk. The event-free survival for the whole group in this study was $95 \%$ based on the observation of five months to six years. All low and intermediate risk patients showed hematologic remission from the beginning of induction (Ia or Ia'); two out of four high

Table 2. Most common toxicities during treatment regimen (number of patients was 20 , total number of toxicity was 187 )

\begin{tabular}{lcc}
\hline Toxicity & $\mathrm{N}$ & $\%$ \\
\hline Hematologic & & \\
$\quad$ Neutropenia & 80 & 42.8 \\
$\quad$ Platelets & 80 & 42.8 \\
$\quad$ Hemorrhage & 4 & 2.1 \\
Infectious & 3 & \\
$\quad$ Sepsis, bacterial & 1.6 \\
$\quad$ Non-sepsis, bacterial & 4 & 2.1 \\
$\quad$ Anal Abscess & 1 & 1.1 \\
$\quad$ Systemic Fungal Infection & 1 & 1.1 \\
Chemotherapeutic & & \\
$\quad$ Asparaginase-induced allergic reaction & 5 & 5.7 \\
$\quad$ Asparaginase-induced pancreatitis & 2 & 1.7 \\
$\quad$ Hypertension & 1 & 1.1 \\
$\quad$ Mucositis & 6 & 6.9 \\
\hline
\end{tabular}

risk patients showed hematologic improvement at the end of initial induction, and remission after intensive three blocks of consolidation. One very high risk patient, who did get the chance to go through the remission after very intensive consolidation, relapsed with dominant CD33 in very depressed marrow, he died due to sepsis before the reinduction program. It is expected the result to fall off in the subsequent years, but it is still expected comparable to $70-80 \%$ or even better. This study also impressed us that the program of induction I'b and Ib (combination of Ara-c, cyclophosphamide and 6-MP) may be too toxic for some patients, which needed modification. There was no significant side effect during HDMTX therapy. It is very intensive consolidation program for high risk group, which need very vigorous support during the severe marrow depression.

In conclusion, precise patient's stratification into low, intermediate and high risks and risk directed therapy is of prime important to improve event-free survival in children with acute lymphoblastic leukemia. The very intensive and toxic program for high risk group may improve EFS, on the other hand, it may give severe marrow depression with it consequent of infection, sepsis, hemorrhage etc, and possible secondary AML at the earlier time.

\section{References}

1. Nachman JB, Sather HN, Gaynon PS, Lukens JN, Wolff L, Trigg ME. Augmented Berlin-Frankfurt-Munster therapy abrogates the adverse prognostic significance of slow early response to induction chemotherapy for children and adolescents with acute lymphoblastic leukemia and unfovourable presentating features: A report from the Children's Cancer Group. J Clin Oncol 1997; 15:2222-30.

2. Rivera GK, Raimondi SC, Hancock ML, Behm FG, Pui CH, Abromowitch M, et al. Improved outcome in childhood acute lymphoblastic leukemia with reinforced early treatment and rotational combination chemotherapy. Lancet 1991; 337:61-6.

3. Turbergen DG, Gilchrist GS, O'Brien RT, Coccia PF, Sather HN, Waskerwitz MJ, et al. Improved outcome with delayed intensification for children with acute lymphoblastic leukemia and intermediate presenting features: a Children Cancer Group phase III trial. J Clin Oncol 1993;11:527-37

4. Conter V, Arico M, Valsecchi MG, Rizzari C, Testi AM, Messina C, et al. Extended intrathecal methotrexate may 
replace cranial irradiation for prevention of CNS relapse in children with intermediate-risk acute lymphoblastic leukemia treated with Berlin-Frankfurt-Munster-based intensive chemotherapy. The Associazione Italiana di Ematologia ed Oncologia Pediatrica. J Clin Oncol 1995; $13: 2480-2$

5. Protocols and Committee Progress Reports of $8^{\text {th }}$ Annual Meeting of International BFM Study Group, 25-27 April 1997.

6. Chessell JM, Bailey C, Richards SM. Intensification of treatment and survival in all children with lymphoblastic leukemia; results of UK Medical Research Council trial UKALL X. Medical Research Council Working Party on Childhood Leukemia. Lancet,1995; 345:143-8.

7. Pullen J, Boyett J, Shuster J, Crist W, Land V, Frankel L, et al. Extended triple intrathecal chemotherapy trial for prevention of CNS relaps in good-risk and poor-risk patients with B-progenitor acute lymphoblastic leukemia: a Pediatric Oncology Group study. J Clin Oncol 1993; 11:839. 49.
8. Reiter A, Schrappe M, Ludwig WD, Hiddemann W, Sauter S, Henze G, et al. Chemotherapy in 998 unselected childhood acute lymphoblastic leukemia patients. Results and conclusions of the multicenter trial ALL-BFM 86. Blood, 1994; 84:3122-33.

9. Reiter A, Schrappe M, Ludwig WD, Lampert F, Harbott J, Henze $\mathrm{G}$, et al. Favourable outcome of B-cell acute lymphoblastic leukemia in childhood: A report of three consecutive studies of the BFM group. Blood 1992; 80:2471-8.

10. Kaspers GJ, Veerman AJ, Popp-Snijders C, Lomecky M, Van Zantwijk CH, Swinkels LM, et al. Comparison of antileukemic activity in vitro of dexamethesone and prednisolone in childhood acute lymphoblasti leukemia. Med Pediatr Oncol 1996; 27:114-21.

11. Bleyer WA, Sather HN, Nickerson HJ, Coccia PF, Finklestein JZ, Miller DR, et al. Monthly pulses of vincristine and prednisone prevent bone marrow and testicular relapse in low risk childhood acute lymphoblastic leukemia: a report of the CCG161 study by the Childrens Cancer Study Group. J Clin Oncol 1991; 9:1012-21. 